\title{
Engagement
}

Building "Engagement," One Brick at a Time

Advertising Engagement: A Driver of Message Involvement on Message Effects

The Advertising Magnifier Effect: An MTV Study

A Biologically Based Measure of Emotional Engagement: Context Matters

A Disaster Is Contagious: How a Brand in Crisis Affects Other Brands

Measuring the Effectiveness of True Sponsorship

Brand Relationships: Strengthened by Emotion, Weakened by Attention

Engaging the Consumer through Event Marketing: Linking Attendees with the Sponsor, Community, and Brand

Effects of Popular Music in Advertising on Attention and Memory

Methodological and Strategy Development Implications of Decision Segmentation

Marketers Who Measure the Wrong Thing Get Faulty Answers

Review of What Sticks: Why Most Advertising Fails and How to Guarantee Yours Succeeds 


\section{Measuring the Effectiveness of True Sponsorship}

\section{BILL HARVEY}

TRA, Inc.

bhncm@ix.netcom.com

\section{STU GRAY}

Independent Consultant

stugrayresearch@aol.com

GERALD DESPAIN

Next Century Media,

Inc.

gdespain@att.net

Twenty-eight studies were conducted for leading advertisers to measure the persuasion of sponsorship without advertising on the internet. Experimental design maintained identical content except for the sponsorship message in the test group missing from the control group. The two groups were random replicates. Persuasion measures used were those accepted by the advertisers involved as being most predictive of sales. Average lift in purchase intent/brand consideration was 29 percent, which compares to an average lift of 4 percent across all ARS Persuasion tests. Across the 28 studies the results were consistent in 100 percent of cases, with the test group higher than the control group. Statistical significance was achieved in virtually all cases at 95 percent confidence. In a different study, the sponsored content was specifically courseware offered free on the internet by major advertisers. Here the measurement was ROI based on a questionnaire self-report of brand purchase and price paid. Sample size was over 196,000 intab questionnaires with a 65 percent response rate. ROI for sponsored educational content averaged 55:1, about 27 times the published average of all MMA ROI results. The latter study also obtained supplementary measures of satisfaction, increased brand perception, brand promoter, willingness to take future courses, etc., the results of which were highly positive and hence strongly supportive of the ROI results. These studies point strongly to a major role for classical "True" sponsorship in the future of advertising in all media, including internet, linear TV, VOD, mobile, etc.

\section{INTRODUCTION}

Sponsorship is again on the rise, and marketers have called for new efforts by researchers to measure the business value of this form of marketing communications. The methodologies appropriate to making sponsorship accountable are similar to those used for other forms of advertising, and the effects of sponsorship fit within the continuum of effects known as the ARF Model. What causes Persuasion in the sponsorship context appears, however, to be logically different from what causes Persuasion in the advertising context. Advertising appears to work by causing improvements directly in brand perception, whereas sponsorship appears to work by causing improvement directly in the perception of the sponsoring company and often indirectly by halo effect in the brand perception. However, even when brand perception is not affected, sponsorship can increase purchase intent, apparently as result of gratitude toward the sponsor.

\section{BACKGROUND TO THIS STUDY SERIES}

In 1999, Next Century Media was approached by Studio One, a major creator and syndicator of 
sponsored content on the internet and in broadcast outlets, and was asked to develop a methodology for measuring the effects of internet sponsorships. In subsequent meetings with industry associations, including the Association of National Advertisers (ANA), the American Association of Advertising Agencies (AAAA), and American Demographics Magazine, Studio One Networks and Next Century Media organized SEI LLC, whose purpose is to make those methodologies applicable across all media, including television and event sponsorships. The methodology has been applied first to the internet and is expanding, using constant yardsticks across all media. Between 2000 and 2006, SEI has executed 30 sponsorship studies for 12 top advertisers. Twenty-eight of these studies for 10 top advertisers have been completed, and their results are contained in this report.

\section{CURRENT QUESTIONS}

Sponsorships were the original advertising form on radio and television. Sponsored events today generate more total dollars than all media advertising combined (from a combination of sponsor expenditure plus ticket sales). On the internet, sponsorship revenues are expanding faster than banner revenues. In the future, the rise in penetration of personal video recorders [(PVRs) also known as digital video recorders (DVRs)] such as TiVo, as well as the duplication of PVR function by cable and satellite set top boxes is expected to increase the consumer's ability to avoid normal advertising. Pundits are proclaiming that the future shall be a new Golden Age for sponsorship, product placement, and cast presenter commercials, in an effort by marketers to keep up the consumer's diet of marketing messages in face of the new hurdles-avoiding zapping by merging into the programming.
Despite all of the indicators pointing to the need for a clear understanding of the business value of sponsorships, marketers today remain unsure of how sponsorship works and how to properly measure its business value. Marketers see sponsorship as something different from advertising-but there has been no general clarification of how sponsorship differs from advertising, and what this implies in terms of how to make sponsorship accountable. Thus there has been a recent groundswell of interest expressed by advertisers and agencies alike in devising new forms of research to measure the business effects of sponsorships in all media-including events.

\section{HYPOTHESES OF THE SPONSORSHIP EFFECTIVENESS INDEX STUDIES}

1. Sponsorship has recall and persuasion effects like traditional advertising.

2. Sponsorship operates through different cognitive processes than those utilized by traditional advertising.

3. Advertising changes the consumer's perception of a specific product while sponsorship changes the consumer's perception of a specific sponsorwhich can rub off positively on the brands of that sponsor and may increase the willingness to purchase those brands.

4. Sponsorship's positive business effects are maximized when:

a. The target audience is highly involved in the subject of the program or event being sponsored.

b. That audience perceives there to be a scarcity of content in the subject area relative to their appetite for it.

c. The program/event is executed so as to produce a high level of satisfaction with the material by the audience.

\section{METHODOLOGY}

When internet users click on a link to a sponsored program, they are intercepted by an invitation screen.

Before they are admitted to the program, they must answer yes or no to a question as to their willingness to answer a few questions "to help us improve the program," which they will be asked upon leaving the program. They may be offered an incentive ranging from a free magazine to a \$15 gift certificate at a popular book chain website, depending on the degree of the advertiser's willingness to incent respondents.

Users answering "no" are allowed to go to the program and are not contacted again. Users answering "yes" are also allowed to go to the program, and a random half of them are sent to a version of the program where the sponsor is not mentioned (the control group). Everything else about the program is identical across the exposed group and the control group. As respondents leave the program by any means (e.g., click on a banner, hit the back button, etc.), they receive a short onscreen questionnaire, which is the same for both the exposed group and control group. A person's status (agreed to participate or not, control or exposed group, already responded to questionnaire or not) persists across multiple sessions to prevent duplication of participants or showing sponsorship logos to the control group.

The questionnaire begins with questions about the editorial content, and how it might be improved. It then goes on to questions relevant to measuring sponsorship effectiveness, which are adapted for each sponsor's studies to reflect communications measures that the advertiser has found to be most predictive of sales, and which are therefore routinely used to assess advertising performance in tracking studies and in commercial pretesting. The 
difference in these measures is attributed to the effect of sponsorship, as all other variables have been held constant.

SEI's software can be calibrated so that all users clicking to go to a sponsored program may be intercepted, or a specific percentage of them can be intercepted.

\section{FINDINGS}

\section{IAB study, 2003}

During April-September 2003, the Interactive Advertising Bureau in conjunction with CondéNet, Forbes, Primedia, Register.com, Studio One Networks, Terra Lycos, and Yahoo, under the sponsorship of Volvo through Euro RSCG Circle.com, engaged SEI LLC to conduct a major industry landmark study of the two main types of internet sponsorship, True Sponsorship as defined above versus Common Sponsorship (the latter consisting of all other forms of internet sponsorship, differentiated from true Sponsorship mainly by having more than one advertiser visible on the page).

Figure 1 shows what True Sponsorship looked like in this Volvo test. Note the absence of any other advertising on the page, and the fact that the Volvo appearance on the page eschewed the opportunity to "sell" Volvo advantages and merely stated that Volvo was the sponsor, connoting that this coverage of the New York Auto Show would not have appeared were it not for Volvo having paid for it on behalf of the audience.

Figure 2 is an example of how Common Sponsorship appeared in this test, and often appears on the internet (see Figure 2). Note the multiple advertisements on the page for other advertisers, as well as hard sell advertisements for Volvo, plus the identical Volvo appearance as in True Sponsorship.

In this study the lift in Willingness to Consider Volvo was compared between the two forms of sponsorship. Of course,

\begin{tabular}{|c|c|c|}
\hline- & & 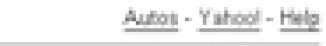 \\
\hline Welcone, Guast & \multicolumn{2}{|c|}{ 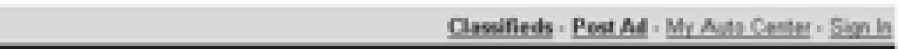 } \\
\hline \multicolumn{3}{|l|}{ Yahoof Autos } \\
\hline \multicolumn{3}{|c|}{ Ailss Hume? ? Researdh } \\
\hline Features & \multicolumn{2}{|l|}{2009 Auto Shows } \\
\hline Aweangh & \multirow{2}{*}{\multicolumn{2}{|c|}{ 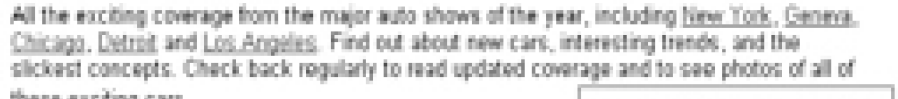 }} \\
\hline - Vincrenga & & \\
\hline - Cucandinise & \multirow{4}{*}{ 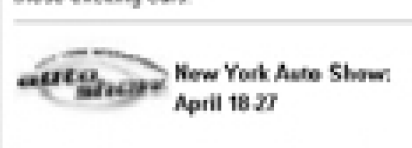 } & \multirow{2}{*}{$\begin{array}{l}\text { NY Auto Show conerage } \\
\text { sponsored by }\end{array}$} \\
\hline - Whad Cin lowili & & \\
\hline - Conumar Hénar. & & vonuo \\
\hline - that inthiclen & \multirow{7}{*}{\multicolumn{2}{|c|}{ 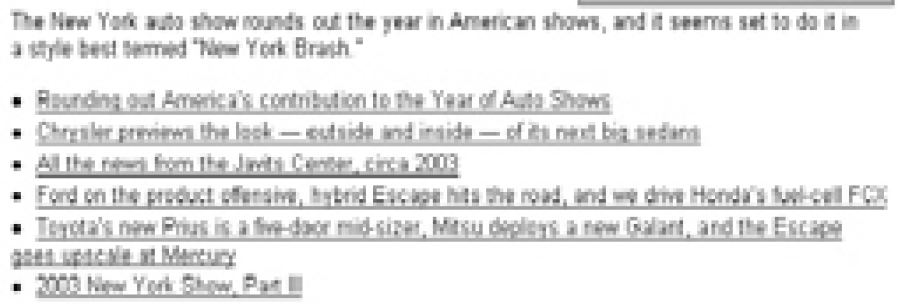 }} \\
\hline Bysacar & & \\
\hline Sell a Car & & \\
\hline Cur Finarding & & \\
\hline Car lmannos. & & \\
\hline Gedilifaputs: & & \\
\hline Muimain Cass & & \\
\hline Talk Cins & \\
\hline & \multicolumn{2}{|c|}{ 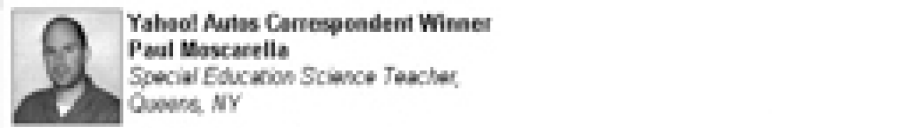 } \\
\hline & \multicolumn{2}{|c|}{ 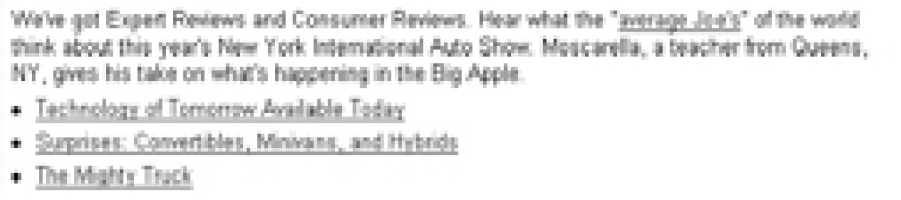 } \\
\hline
\end{tabular}

Figure 1 True Sponsorship

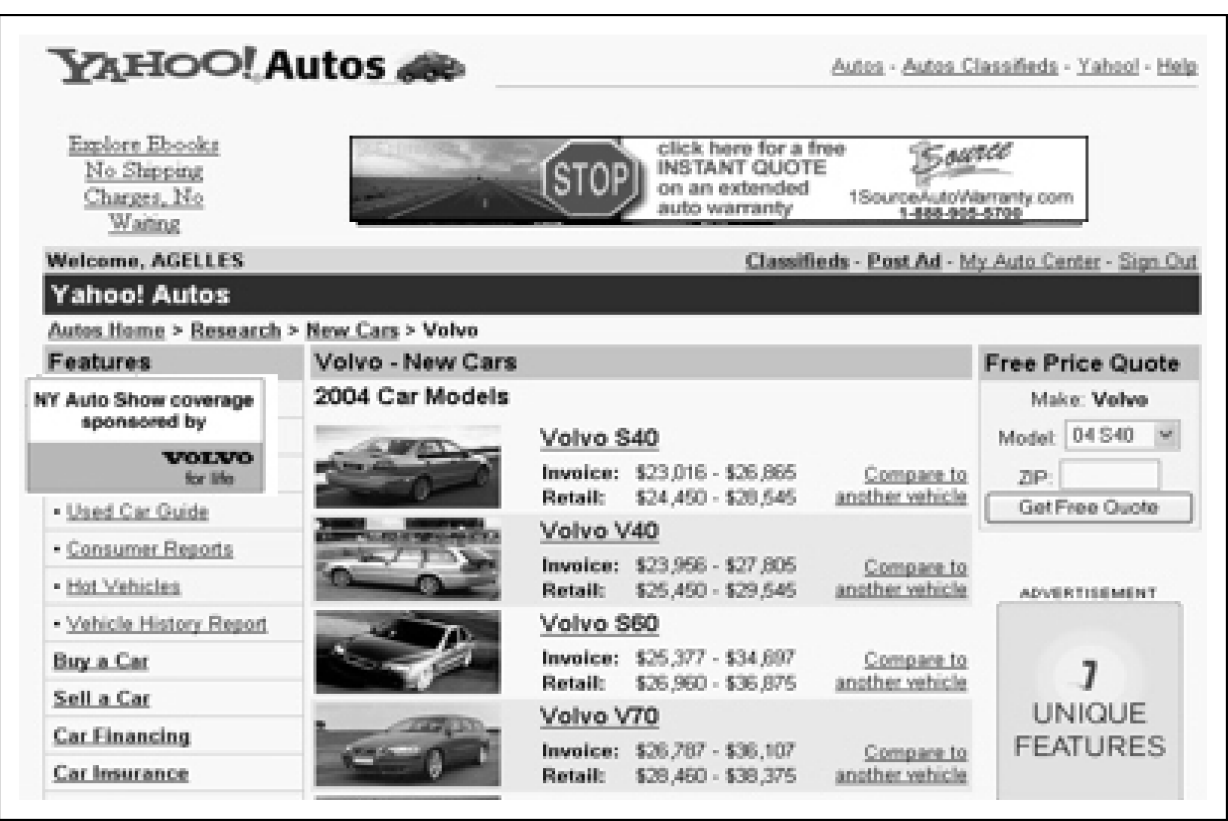

Figure 2 Common Sponsorship 
respondents did not know Volvo was behind the study, and Volvo was not mentioned by name anywhere in the questionnaire or in the recruitment screen. All SEI LLC studies utilize this same double-blind methodology ("double" meaning that neither respondents nor interviewers know the identity of the study sponsor-in the case of SEI there are no interviewers so only respondents need to be kept in the dark).

The results clearly show a dramatic lift in Willingness to Consider Volvo created by True Sponsorship, with no significant change in Willingness to Consider produced by Common Sponsorship (see Table 1).

\section{Consideration set}

The key success measure for many advertisers is Consideration Set. The consideration set is that group of brands within a product category that the particular consumer is willing to buy. The brand decision at each purchase occasion balances mood, situation, availability, price/promotion, and advertising recency-among the known factorsto select one brand (or more) out of the present consideration set. To be in this set gives a brand a chance of being purchased; to be out of this set is to have a virtually zero chance of being purchased.

\section{The results clearly show a dramatic lift in Willingness to} Consider Volvo created by True Sponsorship, with no significant change in Willingness to Consider produced by Common Sponsorship

Automotive marketers have the following footrule: in buying a new car, the average consumer considers six makes, test drives three, and buys one. This points up the importance of being in the consideration set level of the car buying funnel.

Table 2 shows the combined SEI studies across four different packaged goods brands and four different automotive brands. The comparison is on willing to consider between those who saw the sponsor on the program versus the control group who saw the same program, but without the sponsor being mentioned.

The average lift for packaged goods was 25 percent (one-quarter again as many consumers). The average lift for automotive was 55 percent (half again as many consumers).

\section{Purchase intent for packaged goods}

In SEI studies for four packaged goods products, we asked about purchase in-

\section{TABLE 1}

Willingness to Consider Volvo

\begin{tabular}{|c|c|c|c|c|}
\hline & $\begin{array}{l}\text { Sponsored } \\
\text { (Favorable) }\end{array}$ & $\begin{array}{l}\text { Unsponsored } \\
\text { (Favorable) }\end{array}$ & Lift & Confidence \\
\hline \multirow[t]{2}{*}{ True Sponsorship } & $7.6 \%$ & $1.6 \%$ & $+383 \%$ & $96 \%$ \\
\hline & $(92)$ & $(127)$ & & \\
\hline \multirow[t]{2}{*}{ Common Sponsorship } & $4.4 \%$ & $5.6 \%$ & $-22 \%$ & $75 \%$ \\
\hline & (873) & (841) & & \\
\hline
\end{tabular}

tent, which across these studies increased by an average of +26 percent (see Table 3 ).

\section{Brand perception}

A major clue to the way that sponsorship works is provided by a third measure, Brand Perception. The underpinning of today's Persuasion measurement is a cognitive attitude shift model in which (1) attitude is a predisposition to behavior, and therefore predictive of behavior, and (2) the predisposition to buy a brand is the mathematical resultant of (a) the desirability weights that a specific consumer places on various benefit dimensions of a specific product category and (b) the degree to which that consumer perceives each brand in the category in terms of its ability to deliver each of those benefits.

Horace Schwerin, Al Achenbaum, Russ Haley, Jack Landis, and many others (Young, 2001) deserve credit for establishing this important model (not the only important model) of how advertising works. The present work is aimed at helping sponsorship catch up with advertising in terms of having a similar level of understanding of how the process works.

Within the latter context, in the sponsor's product category, having one's brands perceived as one of the best in terms of product attributes would be a good thing; therefore, we would expect that if sponsorship worked exactly like advertising, then given the positive results seen above, we would expect that the perception of the sponsor's brands as one of the best would always be higher in the exposed group 


\section{In SEI studies for four packaged goods products, we asked about purchase intent, which across these studies increased by an average of +26 percent.}

than in the control group. For some studies, we asked the respondents to rate their attitude toward the sponsoring brand. Although the average across all brands showed a +23 percent lift (Table $4 a$ ), one advertiser did not show a significant positive lift in product attribute perception among those exposed to the sponsorship (decline of -6.0 percent), although purchase intent increased by +38.9 percent (Table 4b). From this case, and logic, we deduce that sponsorship increases willingness to do business with the sponsor to whom one has gratitude, and this generally, but not always, also lifts brand perception by the well-known "halo effect," which operates to maintain perceived selfconsistency, and thereby minimize cognitive dissonance (Beckwith and Lehmann, 1975).

\section{Conscious sponsorship impact on opinion of sponsor}

These substantial numbers (see Table 5) corroborate the dynamic changes implied by the exposed/unexposed comparisons,

\section{TABLE 2}

True Sponsorship Effect on Consideration Set for a Car Maker

\begin{tabular}{|c|c|c|c|c|}
\hline & Sponsored & Unsponsored & Lift & $\begin{array}{l}\text { Confidence } \\
\text { Level }\end{array}$ \\
\hline \multicolumn{5}{|l|}{ Packaged goods } \\
\hline Intab sample size & 1,621 & $\begin{array}{r}1,560 \\
\ldots \ldots \ldots \ldots\end{array}$ & & \\
\hline Considering sponsor & $63.7 \%$ & $51.2 \%$ & $\begin{array}{l}+24.6 \% \\
+\ldots \ldots\end{array}$ & $100 \%$ \\
\hline \multicolumn{5}{|l|}{ Automotive } \\
\hline Intab sample size & 480 & 505 & & \\
\hline Considering sponsor & $11.7 \%$ & $7.5 \%$ & $+55.0 \%$ & $97 \%$ \\
\hline
\end{tabular}

\section{TABLE 3}

\section{True Sponsorship Effect of Intent to Purchase}

\begin{tabular}{|c|c|c|c|c|}
\hline $\begin{array}{l}\text { Intent to } \\
\text { Purchase Sponsor }\end{array}$ & Sponsored & Unsponsored & Lift & $\begin{array}{l}\text { Confidence } \\
\text { Level }\end{array}$ \\
\hline \multicolumn{5}{|l|}{ Packaged goods } \\
\hline Intab sample size & 1,595 & 1,533 & & \\
\hline Intent to purchase & $39.1 \%$ & $30.9 \%$ & $+26.3 \%$ & $100 \%$ \\
\hline
\end{tabular}

and indicate that the audience was at least in some cases consciously aware of how the sponsorship influenced them. These supplementary findings triangulate the basic findings and lend credence to the explanation of an underlying appreciation/gratitude effect driving the process of persuasion via sponsorship (see Conclusions below).

\section{Summary of SEI studies}

Between 2000 and 2006, SEI has run sponsorship studies on numerous publisher sites, and a dozen brands. Although the criteria for measuring advertising effectiveness vary by brand/product type, the studies consistently show a positive lift of sponsorship effectiveness between the control group and those exposed to the sponsorship (see Table 6).

\section{FINDINGS OF RELATED STUDIES eVoice study}

In 2000, Next Century Media (NCM) conducted a study outside of the SEI series that involved a case of True Sponsorship. eVoice was a company (now absorbed into AOL) that offered consumers, mostly teenagers, free voicemail in exchange for their willingness to listen to a single advertising message prior to the receipt of their voicemail messages.

For a snack food brand of a major packaged goods company, NCM recommended that the advertising message be replaced by a message that would be construed as beneficial to the listener. This was a 30 second local event music concert schedule customized to the local market of the listener, and tied into the fact that the same snack food brand was a frequent sponsor of such music events.

A random control group received no such message so that the pre-post changes in attitudes toward the snack food brand could be compared between the exposed and control group. 


\section{Although the criteria for measuring advertising effectiveness vary by brand/product type, the studies \\ consistently show a positive lift of sponsorship effectiveness between the control group and those}

\section{exposed to the sponsorship.}

The findings of the eVoice True Sponsorship versus control group are:

- 140 percent lift in top of mind awareness of brand $X$,

- 26 percent lift in purchase intent toward brand $\mathrm{X}$
- 18 percent lift in claimed purchase of brand $X$, and

- 19 percent lift in "brand $X$ is cool/ hip/trendy."

The next month $239 \mathrm{TV}+288$ print gross rating points + in-school advertising/ promotion produced only a 2 percent increase in Purchase Intent on the control group-versus 26 percent for the sponsorship (although these heavy media did produce a higher increase in Top of Mind Awareness, 190 percent).

\section{Powered study}

In 2005, NCM conducted a study for a company Powered.com, which creates online educational experiences sponsored by advertisers such as Sony, HP, and others.

In 2005 , over a million $(1,253,495)$ people opted-in to these educational resources at client sites. Educational resources are offered on the website of the sponsoring brand. Powered's clients aggregately

\section{TABLE 4a}

True Sponsorship Effect on Product Attribute Perception

\begin{tabular}{|c|c|c|c|c|c|c|}
\hline \multirow[b]{2}{*}{ Product Category } & \multicolumn{2}{|c|}{ Sponsored } & \multicolumn{2}{|c|}{ Unsponsored } & \multirow[b]{2}{*}{ Lift } & \multirow[b]{2}{*}{ Confidence } \\
\hline & Intab Sample & Favorable & Intab Sample & Favorable & & \\
\hline Household products ${ }^{a}$ & 125 & $35 \%$ & 111 & $15 \%$ & $+130 \%$ & $100 \%$ \\
\hline Household products ${ }^{\mathrm{b}}$ & 156 & $46 \%$ & 173 & $32 \%$ & $+41 \%$ & $99 \%$ \\
\hline Pet products ${ }^{\mathrm{c}}$ & 156 & $41 \%$ & 144 & $28 \%$ & $+44 \%$ & $98 \%$ \\
\hline Pet products ${ }^{\mathrm{c}}$ & 318 & $32 \%$ & 300 & $25 \%$ & $+28 \%$ & $95 \%$ \\
\hline Pet products ${ }^{\mathrm{c}}$ & 266 & $30 \%$ & 281 & $27 \%$ & $+13 \%$ & $62 \%$ \\
\hline Prepared food ${ }^{d}$ products & 243 & $39 \%$ & 255 & $42 \%$ & $-6 \%$ & $43 \%$ \\
\hline Total brand perception & 1,264 & $36 \%$ & 1,264 & $29 \%$ & $+23 \%$ & $100 \%$ \\
\hline
\end{tabular}

a Brand perception: Score 7, 8, 9 on scale of 1-9, average "Good Tips" and "Cares about Moms"

${ }^{b}$ Positive attitude toward brand $D$

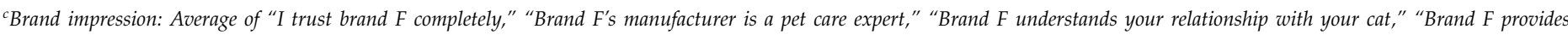
more than just food," "Brand F provides variety."

${ }^{\text {} P e r c e p t i o n}$ one of best or above average

\section{TABLE 4b}

True Sponsorship Effect on Product Attribute Perception and Purchase Intent

\begin{tabular}{|c|c|c|c|c|c|c|c|c|}
\hline \multirow{2}{*}{$\begin{array}{l}\text { Product Category } \\
\text { Prepared food products } \\
\text { Pand }\end{array}$} & \multirow{2}{*}{$\begin{array}{l}\text { Brand } \\
N \\
N\end{array}$} & \multicolumn{2}{|c|}{ Sponsored } & \multicolumn{2}{|c|}{ Unsponsored } & \multicolumn{2}{|c|}{ Measure } & \multirow[b]{2}{*}{ Brand perception } \\
\hline & & 243 & $39.1 \%$ & 255 & $41.6 \%$ & $-6.0 \%$ & $42.64 \%$ & \\
\hline Prepared food products & N & 243 & $18.5 \%$ & 255 & $13.3 \%$ & $38.9 \%$ & $88.64 \%$ & Purchase intent \\
\hline
\end{tabular}




\section{TABLE 5}

\section{Conscious Improved Opinion toward True Sponsor}

\begin{tabular}{|c|c|c|c|}
\hline & $\begin{array}{l}\text { Sample } \\
\text { Size }\end{array}$ & $\begin{array}{l}\% \text { Might } \\
\text { Have Improved } \\
\text { Opinion }\end{array}$ & $\begin{array}{l} \pm \text { Tolerance } \\
\text { Range @ 95\% } \\
\text { Confidence }\end{array}$ \\
\hline Average & 1,039 & $27.6 \%$ & $3 \%$ \\
\hline
\end{tabular}

received $17,422,000$ visits in 2005 . Therefore the opt-ins represent 7.2 percent of visits and an unknown higher percentage of unique visitors.

The surveys used were administered to coincide with the conclusion of the experience, generally 6-8 weeks after it began. Total survey views (offering an opportunity to fill out a questionnaire online) were 299,301, out of which 65.7 percent $(196,603)$ completed the questionnaire.

This response rate is relatively high compared to today's norms. The typical survey today is probably completed by about 25 percent of the predesignated sample. The Nielsen intab response rate, for example, is 24 percent according to the president of CBS research, David Poltrack. The best estimate of response rate on Arbitron's Portable People Meter (PPM) system is 13 percent. Internet intercept interviews today average under 1 percent response rate. So that the high response rate of 65.7 percent for questionnaires associated with Educational Marketing is itself evidence of a high degree of consumer motivation around this experience.

Two important questions asked in these surveys were: "Did you make a purchase as a direct result of taking this course?" and "If you purchased product(s), what was the approximate dollar amount of your purchase?" In 2005 the Powered advertiser sponsors in the sample were consumer electronics manufacturers, and the educational content related to how to get

\section{TABLE 6}

\section{Summary of SEI True Sponsorship Studies-Advertiser's Main Measure}

\begin{tabular}{|c|c|c|c|c|c|c|}
\hline & \multicolumn{2}{|c|}{ Sponsored } & \multicolumn{2}{|c|}{ Unsponsored } & \multirow[b]{3}{*}{ Lift } & \multirow[b]{3}{*}{ Confidence } \\
\hline & Intab & & Intab & & & \\
\hline & Sample & Favorable & Sample & Favorable & & \\
\hline Prepared food products & 822 & $58.6 \%$ & 831 & 48.0 & $+22.1 \%$ & $100 \%$ \\
\hline Food products & 431 & $29.9 \%$ & 362 & $27.9 \%$ & $+7.3 \%$ & $47 \%$ \\
\hline Health products & 243 & $33.7 \%$ & 255 & $24.3 \%$ & $+38.8 \%$ & $98 \%$ \\
\hline Household products & 125 & $\begin{array}{l}34.4 \% \\
. .1 .1 \%\end{array}$ & 112 & $\begin{array}{l}13.4 \% \\
.1 .1 \%\end{array}$ & $\begin{array}{l}+156.9 \% \\
+\ldots \ldots\end{array}$ & $99 \%$ \\
\hline Automotive & 480 & $11.7 \%$ & 505 & $\begin{array}{l}7.5 \% \\
\ldots . . \cdots\end{array}$ & $\begin{array}{r}+55.0 \% \\
+\ldots \ldots\end{array}$ & $97 \%$ \\
\hline Financial services & 82 & $42.7 \%$ & 88 & $27.3 \%$ & $+56.5 \%$ & $97 \%$ \\
\hline Total & 2,183 & $28.9 \%$ & 2,153 & $39.9 \%$ & $+\mathbf{2 8 . 9} \%$ & \\
\hline
\end{tabular}

the best use out of specific products (e.g., one of the categories in the study was digital photography). Each sponsorship provided an appropriate scale of dollar ranges for filling in the multiple choice question regarding amount spent. For example, “Less than \$100," “\$100-\$499," etc.

Per standard marketing research practice, in tabulating the results of these questions the midpoint price within each range was assumed, so that for "Less than $\$ 100$ " the assumed average price was $\$ 50$, and so on. The top scale point was always "Greater than" a certain price, e.g., "Greater than \$2500." The average price was estimated to be 20 percent above the bracket amount, e.g., 20 percent higher than $\$ 2500$, or $\$ 3000$. Because these surveys were completed 6-8 weeks into the experience, some purchases would have been made after the questionnaires were collected, and those purchase effects are therefore not reflected. Hence the ROI estimates here are truncated somewhat. We can estimate the degree of understatement by considering the number of nonpurchasers who indicate that they are likely to purchase in the next 12 months, assuming no overstatement of future plans. The group answering "yes" to the question "Do you plan to purchase in the next 12 months" was 33.0 percent of respondents. This may be compared to the group who reported already making a purchase-20.5 percent. The former (33.0 percent) group was not included in calculation of ROI. If they had been included, the ROI estimates for Educational Marketing could be as much as 2.6 times higher than the reported purchase level $(20.5+33.0$ divided by $20.5=2.6$ ).

For consumer electronics, a considered purchase made relatively infrequently, the consumer generally remembers the price paid with high accuracy for some time thereafter. If on average the purchase was made halfway into the 


\section{TABLE 7}

\section{ROI of Educational Marketing}

\begin{tabular}{|c|c|c|c|}
\hline Advertiser & Investment & $\begin{array}{l}\text { First 6-8 } \\
\text { Week Sales }\end{array}$ & $\begin{array}{l}\text { First 6-8 } \\
\text { Week ROI }\end{array}$ \\
\hline A & $\$ 1,100,000$ & $\$ 34,016,755$ & 30.9 to 1 \\
\hline $\mathrm{B}$ & $\$ 371,158$ & $\$ 11,350,703$ & 30.6 to 1 \\
\hline $\mathrm{C}$ & $\$ 465,310$ & $\$ 23,917,916$ & 51.4 to 1 \\
\hline $\mathrm{D}$ & $\$ 701,190$ & $\$ 76,430,445$ & 109.0 to 1 \\
\hline Average & $\$ 659,415$ & $\$ 36,428,655$ & 55.2 to 1 \\
\hline
\end{tabular}

6-8 week period, then the data were collected on average less than a month after the purchase was made. We would expect therefore that the great majority of consumers checked the right box in terms of amount spent.

The findings for survey cooperators were projected to total enrollment using a projection factor of 6.37 , because the total opt-in base was 6.37 times as large as the intab questionnaire sample base.

ROI is defined in this analysis as incremental short-term sales revenues divided by investment.

\section{FINDINGS-ROI}

In all Table 7 findings, NCM has masked the identity of the advertisers to protect their proprietary information.

The numbers in Table 7 compare very favorably to the existing benchmarks. For example, Johnson (2005) states: “For 2005, an investment of \$1 in DM ad expendi- tures will return, on average, $\$ 11.49$ in incremental revenue across all industries." This is only a fifth of the ROI of Educational Marketing.

A more telling comparison relates to "nondirect response" advertising (see Table 8). Ephron and Pollak (2003) published the most extensive analysis of media advertising ROI, based on marketing mix modeling conducted by MMA. Fortyfive brands were covered, of which 25 are packaged goods brands. These 45 brands represent aggregate an annual media adspend of $\$ 777$ million. The average ROI across the 45 brands is 1.93 to 1 . This is only about 3.5 percent of the ROI of Educational Marketing. Probably the most relevant comparison is to non-CPG, and here the ROI of Educational Marketing is $25 \times$ that of non-CPG paid media advertising (nondirect response).

These dramatic ROI differences support the hypothesis that the Educational

\section{TABLE 8}

Summary of 45 MMA Studies of ROI

\begin{tabular}{|c|c|c|c|c|}
\hline Category & $\begin{array}{l}\text { Number } \\
\text { of Brands }\end{array}$ & Media Dollars & $\begin{array}{l}\text { Incremental } \\
\text { Sales Dollars }\end{array}$ & ROI \\
\hline Non-CPG & 20 & $\$ 547,341,687$ & $\$ 1,226,041,600$ & 2.24 to 1 \\
\hline $\mathrm{CPG}$ & 25 & $\$ 229,367,528$ & $\$ 270,654,200$ & 1.18 to 1 \\
\hline Total & 45 & $\$ 776,709,215$ & $\$ 1,496,695,800$ & 1.93 to 1 \\
\hline
\end{tabular}

Marketing version of "gift" sponsorship achieves high ROI as compared to average media, whether or not direct response.

\section{FINDINGS-SATISFACTION}

96.5 percent of respondents were satisfied with the experience.

1. How satisfied were you with the class overall (including class content, level of difficulty, appropriateness to your needs, class format, etc.)?

Total Sample

189,780

A. Completely satisfied $\quad 92,393 \quad 48.7 \%$

B. Very satisfied $\quad 25,970 \quad 13.7 \%$

$\begin{array}{ll}\text { C. Satisfied } & 64,705 \quad 34.1 \%\end{array}$

D. Somewhat dissatisfied $\quad 4,990 \quad 2.6 \%$

E. Dissatisfied $\quad 1,722 \quad 0.9 \%$

90.4 percent of respondents would definitely or probably recommend the experience to a friend.

2. Would you recommend this class to a friend?

Total Sample 189,923
A. Definitely will recommend
$88,311 \quad 46.5 \%$
B. Probably will
recommend
$83,457 \quad 43.9 \%$
C. Might or might not recommend
$4,864 \quad 2.6 \%$
D. Probably will not recommend
$7,030 \quad 3.7 \%$
E. Definitely will not recommend
$6,261 \quad 3.3 \%$

96.3 percent will definitely or probably enroll in another of these experiences.

3. Do you plan on enrolling in any other Learning Center courses? Total Sample 190,534

A. Definitely will enroll $\quad 147,434 \quad 77.4 \%$

B. Probably will enroll $\quad 35,941 \quad 18.9 \%$

C. Might or might not enroll 2,473 $1.3 \%$

D. Probably will not enroll $2,393 \quad 1.3 \%$

E. Definitely will not enroll $2,293 \quad 1.2 \%$ 


\section{FINDINGS-BRAND PERCEPTION}

93.6 percent agree with the statement "I have a more favorable impression of the brand because of this service."

I have a more favorable impression of the brand because of this service.
Total Sample

Strongly agree

Agree

Disagree

Strongly Disagree
113,373

$6,313 \quad 5.6 \%$

$1,005 \quad 0.9 \%$
$35,020 \quad 30.9 \%$

$71,035 \quad 62.7 \%$

31.1 percent are consciously aware that the experience increased their probability of buying the sponsor's brand.

(This question was included in only one sponsor's questionnaire, hence the far smaller sample size.)

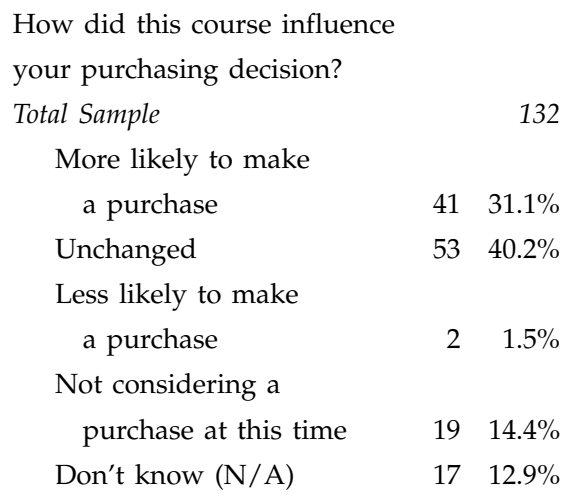

\section{APPLICABILITY TO TELEVISION}

Most of the results presented above were collected from internet tests. This has caused some reviewers to ask the question: how applicable will these results be to television? This is a natural question because television is still the base medium for most major advertisers, garnering about six times the total investment of the internet. And it is particularly cogent today as TiVo-like devices make it easier to avoid TV commercials, and as Video on Demand (VOD) reaches into more homes-many of the same homes with PVRs. VOD is a logical new venue for advertising in any of several forms: interruptive commercials, which the viewer would be expected to tolerate in order to gain a discount or even a free viewing of what otherwise would be a paid experience; and/or True Sponsorship, where the viewer would be able to watch without commercials, and potentially where the advertising effectiveness might potentially exceed the use of interruptive commercials, based on the results seen above.

In this section, therefore, we will present the results for True Sponsorship that we have thus far accumulated within television.

\section{Hooper studies}

In 1968, we were privileged to work on a C.E. Hooper project for a pet food advertiser to measure the effects of a sponsored Special on CBS in prime time. The cast presenter commercials were seamlessly integrated into the program. Hooper was measuring the scatter plan for that advertiser as well and applied the same on-air testing methodology to measuring the Special. The attitude shift, and commercial recall measures for the Special were approximately three times the scatter plan averages. In the latter case, what was being measured was a combination of product-sell commercials plus sponsorship. One indeed wonders what the recall and attitude shift results would have been if the sponsorship did not include product sell commercials. Today, sponsorship generally does not include product sellalthough perhaps it might in the future if the combination turned out to be as potent in general as in the case just cited. This potential potency suggests that the industry develop its sponsorship measurement tools so as to be able to distinguish causes and effects to this degree-i.e., separating out the effects of sponsorship itself from accompanying product sell advertising, if any.

In the same year, we were also fortunate in participating in another Hooper study, which used approximately 250,000 coincidental calls to measure the immediate recall of TV commercials from $10 \mathrm{AM}$ to $10 \mathrm{PM}$ in each local time zone. By 1968 there were only a handful of sponsored programs left on television, as the scatter plan had become the dominant TV media strategy. The immediate commercial recall on these sponsored programs was about 2.5 times the average scatter plan level.

\section{CBS Norman Hecht Research Studies}

In 1990, CBS commissioned Norman Hecht Research (www.normanhechtresearch.com) to conduct a series of studies measuring the effects of five prime-time TV Specials. The advertisers were Anheuser-Busch, AT\&T, Chrysler, GM, Hallmark, McDonald's, Pepsico, Reebok, and Valvoline. The Top of Mind Brand Awareness was increased up to +230 percent with a median increase of +17 percent. Top of Mind Advertising Awareness was increased up to +500 percent with a median increase of +24 percent. The most significant measure, at the persuasion level, was a Purchase Intent increase of up to +40 percent with a median increase of +20 percent. As a benchmark, at about the same time, one of the leading commercial pretesting companies, ARS (www.ars-group.com), found that persuasion increase caused by the average TV commercial tested was on the order of magnitude of +4 percent.

\section{SURPRISING MAGNITUDE OF RESULTS-LIKELIHOOD OF REPLICATION IN PRACTICE}

There is little question that the magnitude of the results of these tests is surprising. Most tests of new advertising approaches, whether creative or media or both, whether strategic or executional, do not produce results of such striking magnitude. Therefore it is reasonable to ask whether the 
average practitioner is actually capable of achieving such results.

We do not profess to have an uncanny degree of creative talent, nor can the authors claim very much credit for the content that, when sponsored according to the precepts of True Sponsorship (see Recommendations section below), produced these results. A great many people were responsible for the programming involved in these tests. Logic suggests that the mix of creative talents involved ranged from high to low and did not deviate extraordinarily from the typical range among practitioners.

We conclude from these considerations therefore that the typical practitioner is quite capable of enjoying the large magnitude effects found in these studies, simply by following the "rules" as laid out herein, especially in the Recommendations section below.

\section{CHARACTERISTICS OF THE CONTENT PRODUCING THESE RESULTS}

The content producing these results varied across a spectrum. However, a common element in many of the programs involved is that they stood out from most programs either by (in the case of the television programs studied) being "Specials" or (in the case of the internet programs studied) by providing useful information.

Among the internet programs yielding the highest results, the utility of the information provided was conjoined by a degree of positive surprise at the sponsor's honesty and integrity as evidenced by the sponsor's willingness to allow positive information to be included about the sponsor's competitors. This was, for example, the case with regard to the Volvo sponsorship, in which all of Volvo's competitors were showcased in the pages that Volvo sponsored, because the program was coverage of the New York Auto Show. It was also the case for another sponsorship, but the details of that program cannot be revealed without trespassing on the sponsor's proprietary information. Other recent NCM studies in another field (Behavioral Targeting) also suggest that positive surprise is an element that can be of extreme value to advertising.

\section{WHAT IS TRUE SPONSORSHIP?}

There is an unfortunate tendency for some media to misuse the term Sponsorship. What then do we consider to be "True" Sponsorship? We provided an initial definition at the outset of this report, and here we will expand upon that definition with the intent of rounding out the reader's understanding of the critical success factors to the use of this marketing method. A True Sponsorship has:

- Exclusivity/Visibility. There is a single sponsor. There is no advertising for any other brand. It is easy to see the sponsorship credit. It is not a True Sponsorship if it is difficult to see the sponsorship logo because it is too small, poorly placed on the page, or is lost among regular advertisements on the page.

- Emotive Connection. It is perceived as giving the user a no-strings-attached gift of valued content. It is not a True Sponsorship if it is promotion for a brand. It is not a True Sponsorship if there are hidden or obvious product plugs in the program/editorial content. It is not a True Sponsorship if there is hard sell advertising for the sponsor or if what is meant as sponsorship to the consumer looks like just more advertising.

SEI LLC has tested a variety of different modes of sponsorship, comparing them on ascending and descending levels of messaging, creative, integration, and exclusivity.

\section{RECOMMENDATIONS}

Following are some implications for sponsored programming/events that we have drawn from our findings:

- Make sure that your sponsorship of the content is VISIBLE.

- If appropriate, someone involved in the program/event might THANK the sponsor for sponsorship of the program/ event.

- This "Thanking" might be carried over to advertising and PR for the program/ event.

- Be wary of the potential dilutive effects where there are multiple sponsors for the same program/event.

- Adhere to the rules of True Sponsorship-the gift of real value to the audience.

- Make sure that the audience will not perceive your sponsorship as merely another form of advertising.

\section{SUMMARY OF RESULTS}

As sponsorship remains an important marketing element with the promise of playing an even larger role in the future, the present work began with the objective of developing tools with which to quantify the business building effects of sponsorship. At the present stage of this endeavor, some intriguing findings have emerged, which are perhaps worth discussing in terms of their potential implications.

The first hypothesis was that Sponsorship has recall and persuasion effects like advertising does. The SEI studies appear to confirm the existence of a persuasion effect.

The second hypothesis was that Sponsorship operates through different cognitive processes than those utilized by traditional advertising. Although it is too soon to draw any firm conclusions, there does indeed appear to be support for this 
hypothesis. If it were advertising, sponsors ought not to have seen inconsistent results on brand perception along with consistent and dramatically positive results on consideration set and purchase intent. As marketers have long suspected, sponsorship appears to have its positive business effects based on different cognitive processes than straight product sell advertising.

The third hypothesis was that Advertising changes the consumer's perception of a specific product while sponsorship changes the consumer's perception of a specific sponsor-which can rub off positively on the brands of that sponsor in terms of willingness to purchase those brands. This would appear to be the case in the studies of brand attribute perception change. We might speculate that where sponsorship works, the perception of the sponsor changes in the direction of "those are pretty good folks, I ought to try to give them a fair chance."

We might characterize this as Gratitude or Appreciation. Scales such as Trust, Liking, and Respect might also measure this dimension. The perception of the sponsor has changed in a positive way, and as hypothesized, that change in perception of the sponsor-although the perception of the brands did not change-did positively change the consumer's willingness to buy the brands.

\section{TRUE SPONSORSHIP AND ENGAGEMENT}

One of the most encouraging signs in marketing today is the immense shift in thinking from rote impressions-based brand planning, to the concept of Engagement. If one traces this back all the way, it was 1953 when the best minds in the industry, pulled together by ARF, began work on the ARF Model. The Model has always been aimed at getting past the stuck point-the fixation on vehicle impressions-to instead plan, optimize, buy, and post-evaluate based on something closer to ROI; specifically, some practical surrogate that can affordably and reliably be measured the way media vehicle audiences have always been measured, and yet that predicts ROI. Although implicit in the Model for half a century, ARF has now made that core intent explicit. As we dig deeper into Engagement, we invariably discover that it has many moving parts: the length of time we can get a prospect to stay with a brand's messaging, the emotional bonding that all-too-rarely connects prospects and brands, physical interaction by clicking, and so on. Of these, perhaps the most meaningful is the emotional, nonrational dimension of Engagement-surely this is one of the main implications of Gerry Zaltman's work in dissecting how purchase "decisions" are really made. What we find in the course of studying True Sponsorship is that, when sensitively executed, it is a reliable way to engender emotional Engagement between a brand and its prospects.

\section{CONCLUSION}

In looking at the present work in the context of the updated ARF Model, we would ascribe the primary sponsorship effect analyzed herein as belonging within the Persuasion Level. It is a special case of persuasion where the people behind a brand become more attractive rather than the brand itself becoming directly more attractive through the increased perception of one or more of its valued benefits.

Don Schultz and Scott Bailey, in their provocative article "Customer/Brand Loyalty in an Interactive Marketplace" (Schultz and Bailey, 2000), make profound references to Aristotle's concept of distributive justice, and its derivative, J. Stacy Adams' concept of inequity in social exchange. A consumer may change behavior based upon a perceived inequity in a situation. One such perceived inequity situation might be feeling grateful for a sponsor having brought me a program, while I have not recently considered buying that sponsor's product.

These studies indicate that the sponsorship of content can cause audiences exposed to increase their willingness/ intention to buy the sponsor's productnot a surprising finding because that has always been the expectation that causes advertisers to use sponsorship. However, the uncertainty as to this outcome has held sponsorship investments down to a couple of percentage points of total advertising expenditures. This accumulating body of work ought to give advertisers more certainty as to the return on sponsorship investments and therefore lead to marketing allocation shifts in the direction of sponsorship that reflect the higher levels of persuasion found in this type of marketing communication as compared to similar measures taken of, for example, television commercials.

The empirical proof of performance that has always been missing in this form of marketing communications comes at the right time. Looking ahead, it is expected that television audiences will become increasingly able to avoid exposure to television commercials through the use of the digital version of VCRs started by TiVo, and today beginning to be built into cable and satellite set top boxes. In response, advertisers and their agencies have begun to develop more entertaining commercials, increasing use of product placement, self-selected long-form programercials, and in this mix, sponsorship should also rise to compensate for the lost commercial impressions. The data we have collected support the wisdom of using sponsorships more in the future as a way of merging with the programming to avoid zapping, and at the same time actually increase persuasion effects per dollar over current average marketing methods. 
BiLl HARvey has spent over 35 years leading the way in the area of media research with special emphasis on the New Media. In 1972, Harvey founded New Electronic Media Science (NEMS), a marketing media research consultancy that has served nearly 70 top advertisers and agencies, all major MSOs, virtually all major networks, and all major Hollywood studios in the area of New Media. More recently, in conjunction with IBM and Leonard Matthews, former CEO of Y\&R and of Leo Burnett, Mr. Harvey founded Next Century Media. Next Century Media began as the leading interactive media advisor to advertisers, advertising agencies, entertainment and media companies worldwide, and has now evolved into an enabler and service provider for addressable TV commercials and TV clickstream measurement. Through his two companies, he has been involved in every major New Electronic Media trial in the United States since 1975 and many other trials around the world. He has brought more advertisers and agencies into more Interactive TV trials than everyone else in the world combined. Mr. Harvey has authored Mind Magic, a book on selftransformation, which has been used as a course text at 34 universities including NYU and UCLA. A popular speaker at media and futurist conferences around the world, he has written, and been the subject of, numerous articles in a wide range of consumer and media trade publications.

STu GraY is an independent consultant in the field of media research. His clients have included Arbitron, the California Department of Justice, the Center on
Alcohol Marketing and Youth, Cplus3 TV, Knowledge Networks Statistical Research, Lifetime Television, NPD, OMD, Studio One Networks, TV Guide, and Ziff Davis. Mr. Gray was previously senior vice president, director of media resources of BBDO New York. He joined BBDO in 1988 as vice president, director of media research and was elected a senior vice president in 1991. He has also served as vice president of research for Showtime, RCA Selectavision, and NBC

Television, and as director of media research for Wells Rich Greene. Mr. Gray is a graduate of the Baruch School in New York. He has served on the faculty of New York University, The New School, and Brooklyn College Graduate School of Radio/TV. He has also served on the Editorial Advisory Board of the ARF's Journal of Advertising Research.

Gerald Despain has a background in mathematical optimization combined with advanced database technology while working for Honeywell and Groupe Bull computer companies. Over the last decade he has applied these concepts while working in advertising domains to create audience measurement reports, advertising effectiveness studies, and schedule optimization tools.

\section{ACKNOWLEDGMENTS}

American Demographics Magazine, a Crain Advertising Age publication, is the exclusive publishing partner of SEI Inc. with special focus on delivering insight into the study's findings. The SEI findings in this article are presented by kind permission of American Demographics Magazine.

A prior version of this report was originally presented to the Advertising Research Foundation (ARF) in October 2000 and published in the ARF Journal of Advertising Research in November 2002. This updated version includes additional findings developed through July 22, 2006.

\section{REFERENCES}

Beckwith, Neil E., and Donald R. Lehmann. "The Importance of Halo Effects in MultiAttribute Attitude Models." Journal of Marketing Research 12, 3 (1975): 265-75.

Ephron, Erwin, and Gerry Pollak. "Finding the Other Half." Presented at ARF/ ESOMAR Conference, June 2003: [URL: www. ephrononmedia.com].

Johnson, Peter A. Direct Marketing Association 2005 Economic Impact Study. New York: Direct Marketing Association, 2005.

Schultz, Don E., and Scott Bailey. "Customer/Brand Loyalty in an Interactive Marketplace." Journal of Advertising Research 40, 3 (2000): 41-52.

Young, Charles E. A Short History of Television Copytesting. Albuquerque, NM: Ameritest, 2001. 